\title{
Heating control strategy for variable refrigerant flow air conditioning system with multi-module outdoor units
}

\author{
Qiu Tu ${ }^{\mathrm{a}, \mathrm{b}, *}$, Ziping Feng ${ }^{\mathrm{a}, \mathrm{b}}$, Shoubo Mao ${ }^{\mathrm{c}}$, Kaijun Dong ${ }^{\mathrm{a}, \mathrm{b}}$, Rui Xiao ${ }^{\mathrm{a}, \mathrm{b}}$, Wenji Song ${ }^{\mathrm{a}, \mathrm{b}}$ \\ a Guangzhou Institute of Energy Conversion, Chinese Academy of Science, Guangzhou 510640, China \\ ${ }^{\mathrm{b}}$ Key Laboratory of Renewable Energy and Gas Hydrate, Chinese Academy of Science, Guangzhou 510640, China \\ c Haier Air-Conditioning Electronic Co. LTD., Qingdao 266510, China
}

\section{A R T I C L E I N F O}

\section{Article history:}

Received 27 January 2010

Received in revised form 22 April 2010

Accepted 16 June 2010

\section{Keywords:}

Variable refrigerant flow

Inverter

Heating

Control strategy

Frequency

\begin{abstract}
A B S T R A C T
The heating control strategy is key technology for stable and reliable heating operation of variable refrigerant flow air conditioning system with multi-module outdoor units. The synoptic control strategy is that the host module coordinates the system operation and adjusts the operation frequency of every module based on equal frequency allocation principle for suction pressure balance among modules. The heating control model including heating frequency adjustment, module switching condition and frequency allocation model has been built. Considering the discharge pressure disturbance, a certain discharge pressure region is taken as the control objective to adjust the frequency. And considering the lag between pressure and frequency, the restriction condition of discharge pressure and a certain judgment time are introduced into the model to avoid frequent module switching. Furthermore, different frequency allocation models have been built for increase and decrease of module number. In the model, when the module number increases and evenly allotted frequency to every module is less $70 \mathrm{~Hz}$, one or two certain frequencies $70 \mathrm{~Hz}$ are distributed to the pre-existing thermo-on module(s) and the remaining frequency is distributed to ensuing thermo-on module so as to avoid sharp frequency fluctuation and inferior heating effect. Experiments demonstrate the feasibility of the control strategy.
\end{abstract}

(c) 2010 Elsevier B.V. All rights reserved.

\section{Introduction}

Inverter-driven technology has been applied in most variable refrigerant flow air conditioning system (VRF AC). In accordance with indoor thermal load requirement, the compressor rotation speed (operation frequency) and the electronic expansion valve (EEV) opening should be simultaneously adjusted to control compressor output capacity to timely meet the demand for indoor thermal load [1-4]. Less power consumption and better indoor thermal comfort than the common air conditioning system can be achieved by proper control measures. At the same time, high control stability, accuracy of refrigerant mass flow and air outlet temperature due to application of EEV, and diversification of indoor unit styles are increasingly favored by the users.

As the most crucial component of VRF AC, compressor, how to control its output capacity in accordance with its characteristics becomes a key technology for assurance of stable operation and achievement of high energy efficiency. One of the characteristics

\footnotetext{
* Corresponding author at: Key Laboratory of Renewable Energy and Gas Hydrate, Chinese Academy of Science, No.2 Energy Road, Wushan, Tianhe District, Guangzhou 510640, Guangdong Province, China. Tel.: +86 2087211743 ; fax: +86 2087057795. E-mail address: tuqiuky@163.com (Q. Tu).
}

is that its energy efficiency ratio (EER) for cooling and coefficient of performance (COP) for heating at low frequency running are higher than those at high speed running, which was verified by experiments [4]. Thus energy-saving effect can be achieved by appropriate control measures to make the compressor run at the low speed. But the one-sided pursuit of high EER or COP may lead to inferior cooling or heating effects of VRF AC. Thus it is necessary to seek a compromise strategy, better cooling or heating effect and energy-saving operation. On the other hand, VRF AC is composed of one module outdoor unit or multi-module outdoor units and dozens of indoor units, and thermal load requirements vary according to thermo-on number of the indoor units and ambient temperature, so the compressor output capacity needs to be regulated according to load requirements. If the compressors cannot be coordinately controlled, the operation frequency of every module will frequently fluctuate, and continuous regulation of compressor output capability will lead to frequent module switching among different modules, on-off conversion of the compressors, unstable running of the system and even breakage of the compressors. The phenomenon is more obvious for heating operation than that for cooling running because heating and cooling operation are, respectively, controlled by a certain condensation temperature and evaporation temperature, but condensation temperature (saturation temperature corresponding to discharge pressure) and 


\begin{tabular}{|c|c|}
\hline \multicolumn{2}{|c|}{ Nomenclature } \\
\hline$a$ & $\begin{array}{l}\text { operation frequency distributed to pre-existing } \\
\text { thermo-on module }(\mathrm{s})(\mathrm{Hz})\end{array}$ \\
\hline$b$ & $\begin{array}{l}\text { operation frequency equally allocated to every mod- } \\
\text { ule }(\mathrm{Hz})\end{array}$ \\
\hline$f_{i, N}$ & operation frequency of compressor $(\mathrm{Hz})$ \\
\hline$f_{\min }$ & minimal operation frequency $(\mathrm{Hz})$ \\
\hline$f_{\max }$ & maximal operation frequency $(\mathrm{Hz})$ \\
\hline$i$ & $\begin{array}{l}\text { serial number of outdoor unit module. For host mod- } \\
\text { ule, } i=1\end{array}$ \\
\hline$n$ & thermo-on number of modules \\
\hline$N$ & $\begin{array}{l}\text { total module number including thermo-on and } \\
\text { thermo-off modules }\end{array}$ \\
\hline$P_{d}$ & discharge pressure (bar) \\
\hline$P_{0}$ & $\begin{array}{l}\text { discharge pressure objective, } 28 \text { bar for R } 410 A \\
\text { refrigerant (bar) }\end{array}$ \\
\hline$P_{o b j}$ & discharge pressure objective region (bar) \\
\hline$P_{s}$ & suction pressure (bar) \\
\hline$T_{a}$ & ambient temperature $\left({ }^{\circ} \mathrm{C}\right)$ \\
\hline$T_{\text {def }}$ & condenser coil temperature $\left({ }^{\circ} \mathrm{C}\right)$ \\
\hline$T_{d i}$ & discharge temperature $\left({ }^{\circ} \mathrm{C}\right)$ \\
\hline$t_{j}$ & judgment time (min) \\
\hline$T_{\text {oil }}$ & compressor oil temperature $\left({ }^{\circ} \mathrm{C}\right)$ \\
\hline$x$ & $\begin{array}{l}\text { operation frequency distributed to ensuing thermo- } \\
\text { on module }(\mathrm{s})(\mathrm{Hz})\end{array}$ \\
\hline$\Delta f$ & frequency increment $(\mathrm{Hz})$ \\
\hline$\Delta P$ & pressure disturbance (bar) \\
\hline
\end{tabular}

its change range are higher and wider than evaporation temperature (saturation temperature corresponding to suction pressure). Thus the fluctuation range of compressor operation frequency and on-off probability increase in heating mode.

Therefore, it is very necessary to study heating control strategy for solving the key technologies such as the compressor output capacity control, module switching and frequency allocation. Masuda et al. [5] developed a control method for VRF with two indoor units, which could control the refrigeration flow rate of the indoor units individually and respond to the cooling loads. Shi et al. [6-8] proposed the cycle superimposition control method to study the control strategy for VRF AC, which is composed of one module outdoor unit and multi-indoor units. Xia et al. [9] adopted a continuous adaptation of the heat transfer coefficient method to maintain the same superheating during thermo-on periods. In this control strategy, the suitable refrigerant mass flow rate was distributed to each indoor unit by individually adjusting each EEV to obtain required indoor room temperature. And Wu et al. [10] proposed a control strategy for VFR with three indoor units, in which the suction pressure and room air temperature were taken as the control targets to modulate the compressor rotation speed and EEV opening, respectively. Actually, the control strategy is suitable for cooling operation. For heating, the discharge pressure, i.e. condensation temperature is taken as control parameter to adjust the compressor speed. Aynur et al. [11] proposed two different control modes to conduct a field-performance test with VRV system. The experiments showed that the VRF system in the individual control mode provided better thermal comfort for multiple rooms with higher efficiency compared to the master control mode.

With continuous development of VRF control technology, VRF $\mathrm{AC}$ is increasing from one module to multi-module. However, at present, none of the investigations are concerned on the heating control strategy of VRF AC with multi-module due to the technology bottleneck and experimental condition restriction. Some shallow control measures can be seen only from the product technical material. For example, for Dakin VRF AC [12], combination of proportional-integral (PI) control and look-up table method was adopted to control compressor output capacity. In detail, the thermo-on number of compressors and operation frequency versus different load requirements are empirically written in a table in advance, thus the control program is executed according to the table. And then the running frequency is adjusted by PI control method according to a certain condensation temperature. The rough estimation method needs a large number of experiments to determine the running module number and operation frequency verse load requirements in the table.

In this paper, as a study object of VRF AC with multi-module outdoor units, the mathematical model is built to control the compressor output capacity, module switching and frequency allocation so as to reduce experimental workload, ensure the stable and reliable operation, and achieve good heating effects and high energy efficiency.

\section{Heating control strategy}

\subsection{System principle}

The system principle diagram of VRF AC with two modules is shown in Fig. 1. For VRF AC with three modules, the principle diagram is similar to that with two modules.

In Fig. $1, T_{d i}, T_{o i l}, T_{a o}$ and $T_{d e f}$ are, respectively, discharge temperature of the inverter compressor, compressor oil temperature, ambient temperature and condenser coil temperature, which are measured by the relevant temperature sensors. $P_{d}$ and $P_{s}$ are, respectively, discharge pressure and suction pressure measured by the relevant pressure sensors. EEVa1,A and EEVa1,B are EEVs in the outdoor unit. SV1 and SV2 are, respectively, solenoid valves for pressure balance between $P_{d}$ and $P_{S}$ in order to reduce load when the compressors start, and for injection of liquid refrigerant to prevent overheating.

\subsection{Synoptic control method}

For VRF AC with multi-module, every module is an independent system with individual circuit board and control program, and any one module can be set as the host module. If every module regulates the operation frequency in accordance with individual discharge pressure, it will lead to control logic confusion, control complexity and unstable running. Taking into account that the discharge pressures of thermo-on modules are the same almost, in order to solve the above problems, the measure is to regulate the operation frequency for every module by the host module. In detail, the host module and slaver module(s) are defined in a set of VRF AC, in which the host module is connected with indoor units through two-core communication cables, and slaver modules are connected with the host module through three-core communication cables. They can be automatically identified by the DIP in the circuit board through the control program. The host module adjusts the operation frequency according to a certain discharge pressure, 28 bar for R410A refrigerant, i.e. $48^{\circ} \mathrm{C}$ condensation temperature, and allocates frequency to every thermo-on module in accordance with equal frequency allocation principle so as to achieve suction pressure balance and oil balance among modules, and realize stable running.

Assuming that the thermo-on module number and the total module number including thermo-on and thermo-off modules are, respectively, $n$ and $N, n \in[1,3], N \in[1,3]$, and the running frequency is $f_{i, N}, f_{i, N} \in\left[f_{\min ,} f_{\max }\right], i \in[1,3]$, in which $i$ is the serial number of modules, for host module, $i=1$. For most inverter compressors, 


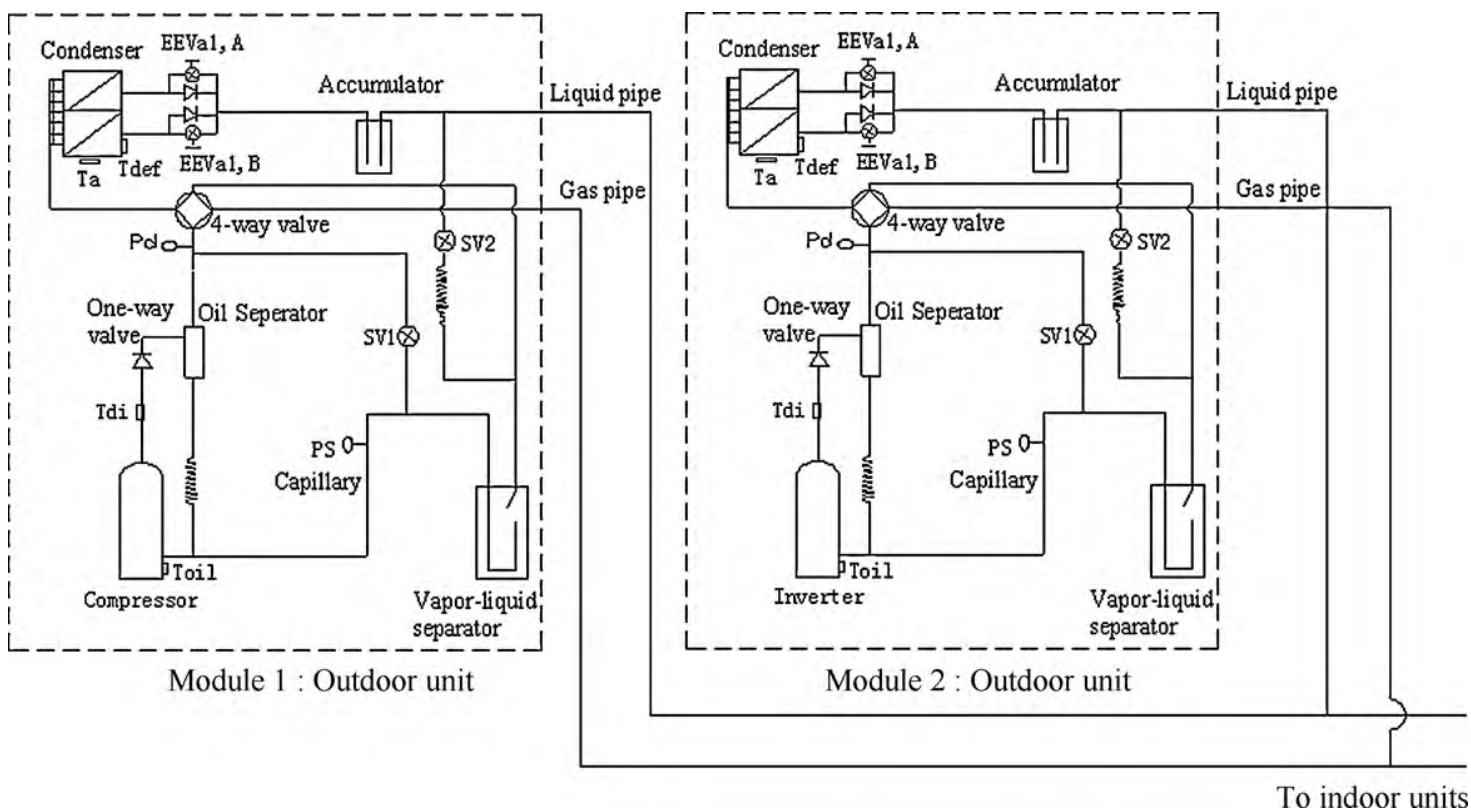

Fig. 1. Schematic diagram of VRF AC with multi-module outdoor units.

the minimal and maximal frequencies are, respectively, $20 \mathrm{~Hz}$ and $120 \mathrm{~Hz}$, namely, $f_{\min }=20 \mathrm{~Hz}, f_{\max }=120 \mathrm{~Hz}$. For thermo-off module, the operation frequency is zero.

And assuming that the current frequency is $f_{i, c u r}$, and adjusted frequency increment is $\Delta f$, the frequency $f_{i, N}$ equally allocated to every module can be written as

$f_{i, N}=f_{i, c u r}+\frac{\Delta f}{n}$

\subsection{Module switching condition and frequency allocation model}

For VRF AC in practical engineering application, the maximum module number is up to three because the stability of the system becomes to be worse with the increase of the module number.

For VRF AC with one or two thermo-on modules, when the total frequency rises to a certain extent and the discharge pressure is lower than the pressure objective, 28 bar, the thermo-off module will start to run so as to heighten the discharge pressure up to the objective. Similarly, when three or two modules run to a certain frequency, and the discharge pressure is still larger than the objective, one of the thermo-on modules will stop so as to reach the pressure objective. The process is defined as module switching.

\subsubsection{Increase of thermo-on module}

The thermo-on module number will increase, i.e. $n \rightarrow n+1$, when the following conditions can be satisfied.

Firstly, at least one module is thermo-off before module switching, i.e. Eq. (2) must be satisfied.

$2 \leq N \leq 3$

$1 \leq n \leq 2$

Secondly, the total operation frequency of all the modules must exceed a certain frequency allocation point, which is expressed as

$\sum_{i=1}^{i=N} f_{i, N} \geq f_{n \rightarrow n+1}$

Here $f_{n \rightarrow n+1}$ is the frequency allocation point from the number $n$ of thermo-on modules to the number $n+1$.
Under the promise of satisfying Eqs. (2) and (3) at the same time, the module switching will be carried out. The running frequency of every module is allotted as

$f_{i, n \rightarrow n+1}=\frac{\sum_{i=1}^{i=N} f_{i, \text { cur }}}{n+1}$

After completion of module switching and frequency allocation, the host module will adjust and allot frequency to every module in accordance with Eq. (1).

\subsubsection{Decrease of thermo-on module}

The thermo-on module number will decrease, i.e. $n \rightarrow n-1$, when the following conditions can be satisfied.

At least two module are thermo-on, i.e. Eq. (5) must be satisfied.

$2 \leq N \leq 3$

$2 \leq n \leq 3$

And the total running frequency must satisfies Eq. (6).

$\sum_{i=1}^{i=N} f_{i, N} \leq f_{n \rightarrow n-1}$

Here $f_{n \rightarrow n-1}$ is the frequency allocation point from the number $n$ of thermo-on modules to the number $n-1$.

Furthermore, when Eqs. (5) and (6) can be satisfied at the same time, the module switching will be carried out, and the running frequency is allotted as

$f_{i, n \rightarrow n-1}=\frac{\sum_{i=1}^{i=N} f_{i, \text { cur }}}{n-1}$

Similarly, the host module will adjust and allot frequency in accordance with Eq. (1) after completion of module switching and frequency allocation.

The mode of module switching and frequency allocation is shown in Fig. 2. 


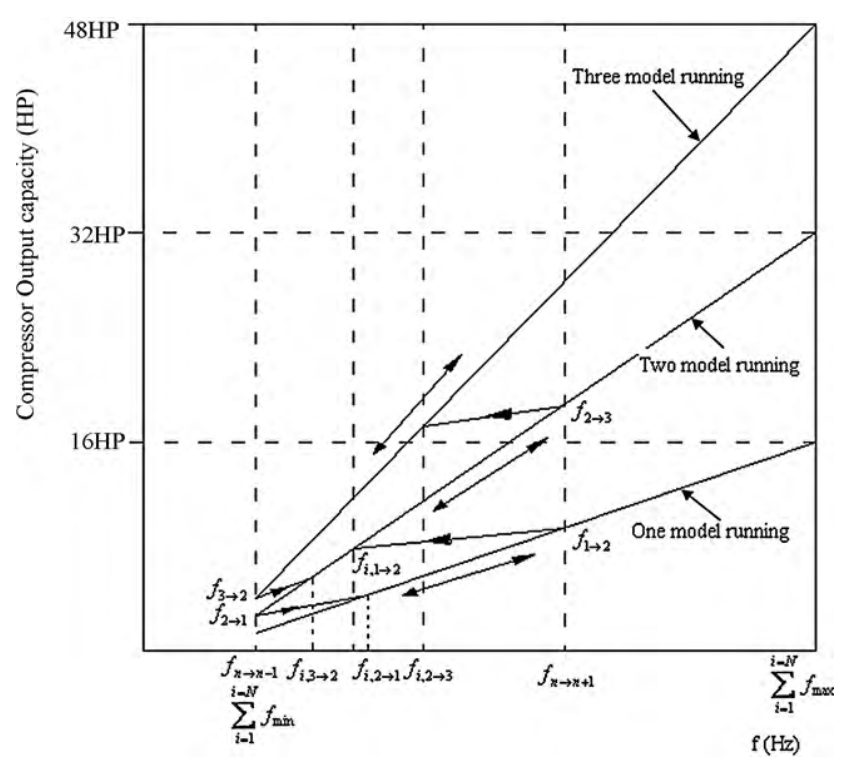

Fig. 2. Mode diagram of module switching and frequency allocation.

\section{Experimental results and analysis}

\subsection{Experimental setup}

A set of VRF AC composed of three-module outdoor units and 23 indoor units was installed in $800 \mathrm{~kW}$ laboratory of Haier Air-Conditioning Electronic Co. LTD. to make long term running experiment, shown in Fig. 3. The types of the three outdoor units are, respectively, KMR-280W/D532A, KMR-335W/D532A and KMR-450W/D532A, whose nominal capacities are respectively $28 \mathrm{~kW}, 33.5 \mathrm{~kW}$ and $45 \mathrm{~kW}$, namely 10 horsepower (HP), $12 \mathrm{HP}$ and $16 \mathrm{HP}$. And the types of the indoor units are shown in Fig. 3, where $\mathrm{E} / \mathrm{M}, \mathrm{G}, \mathrm{N}, \mathrm{Q}$ respectively, means medium static pressure duct indoor unit, wall mounted indoor unit, low static pressure duct indoor unit and four-way cassette indoor unit, and 22, 28, $40,56,71,112,140$ denotes the capacity of the indoor unit, $2.2 \mathrm{~kW}, 2.8 \mathrm{~kW}, 4.0 \mathrm{~kW}, 5.6 \mathrm{~kW}, 7.1 \mathrm{~kW}, 11.2 \mathrm{~kW}$ and $14 \mathrm{~kW}$, respectively.

The distance between the first branch pipe to the outdoor unit was $50 \mathrm{~m} .12$ and 11 indoor units were installed in the first subpipeline and the second sub-pipeline, where the distance between the farthest indoor units to the outdoor unit were, respectively, $107.5 \mathrm{~m}$ and $105.5 \mathrm{~m}$. And every indoor unit was $1 \mathrm{~m}$ away from the individual branch pipe. The system was charged with $70 \mathrm{~kg}$ $\mathrm{R} 410 \mathrm{~A}$ refrigerant. The diameters of main gas pipe as well as liquid

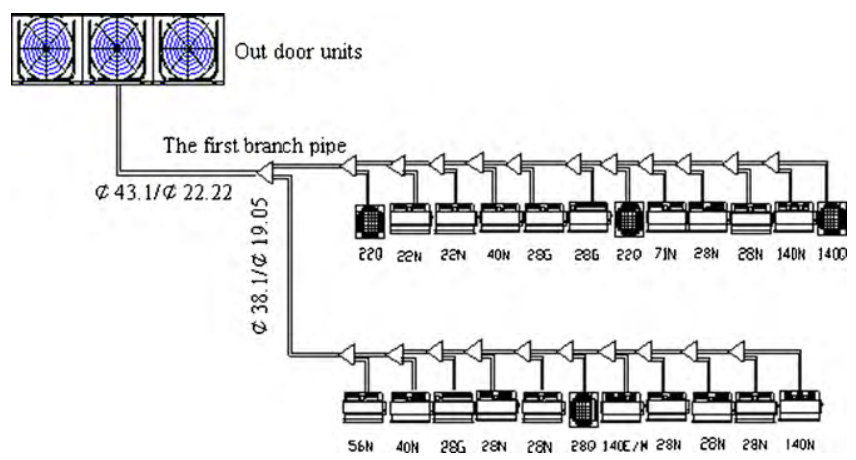

Fig. 3. Installation diagram of experimental setup with three-module outdoor units and 23 indoor units.

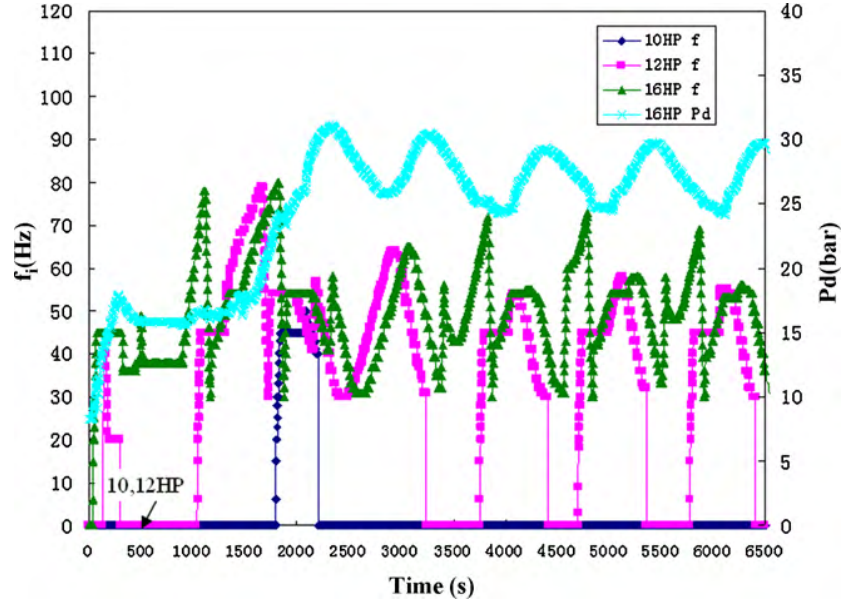

Fig. 4. Experimental results of low temperature heating when only one $140 \mathrm{~N}$ indoor unit was thermo-on.

pipe before and after the first branch pipe were, respectively, $\varphi 41.3 / \varphi 22.22$ and $\varphi 38.1 / \varphi 19.05$.

\subsection{Experimental results and analysis}

In order to make the compressors run at low frequency for the sake of energy-saving, the frequency allocation points are tentatively determined to be $75 \mathrm{~Hz}$ and $150 \mathrm{~Hz}$, respectively, when one module is switched to two modules and two modules are switched to three modules, namely, $f_{n \rightarrow n+\left.1\right|_{n=1}}=75 \mathrm{~Hz}, f_{n \rightarrow n+\left.1\right|_{n=2}}=150 \mathrm{~Hz}$. Thus $f_{i, 1 \rightarrow 2}$ and $f_{i, 2 \rightarrow 3}$ are, respectively, calculated to be $37.5 \mathrm{~Hz}$ and $50 \mathrm{~Hz}$ according to Eq. (4).

Similarly, the frequency allocation points are tentatively determined to be $40 \mathrm{~Hz}$ and $60 \mathrm{~Hz}$, respectively, when the number of modules is switched from two modules to one module and from three modules to two modules, namely, $f_{n \rightarrow n-\left.1\right|_{n=2}}=40 \mathrm{~Hz}$, $f_{n \rightarrow n-\left.1\right|_{n=3}}=60 \mathrm{~Hz}$. Thus $f_{i, 2 \rightarrow 1}$ and $f_{i, 3 \rightarrow 2}$ are, respectively, calculated to be $40 \mathrm{~Hz}$ and $30 \mathrm{~Hz}$ according to Eq. (7).

The ambient dry bulb temperature and wet bulb temperature of outdoor chamber and indoor chamber of the laboratory were adjusted to $-10^{\circ} \mathrm{C} \mathrm{DB} /-15^{\circ} \mathrm{C} \mathrm{WB}$ and $20^{\circ} \mathrm{C} \mathrm{DB} / 15^{\circ} \mathrm{C} \mathrm{WB}$, respectively. Only one $140 \mathrm{~N}$ indoor unit was turn on to make low temperature heating experiment. The experimental results are shown in Fig. 4.

The experimental results in Fig. 4 show that the system ran unstably, pressure and frequency oscillated frequently, and there existed a lag between the discharge pressure and frequency. In detail, during the running process of $16 \mathrm{HP}$ outdoor unit, the discharge pressure did not lift quickly with the increase of the frequency, but rose very slowly. When the module switching condition was obtained, the first slaver module began to run, and then the discharge pressure lifted quickly and exceeded the pressure objective. Subsequently, the running frequency began to decrease, and the condition of decreasing module number was obtained, so the slaver module stopped. The on-off process of the slaver module was performed repeatedly. The experiment also shows that the frequency allocation point is an important parameter to determine the thermo-on module number. If it is set small, the module switching condition can be quickly obtained and the switching process was carried out frequently. Furthermore, analysis of frequent fluctuation shows that a small pressure disturbance will result in frequency oscillation if the frequency is adjusted in accordance with a certain constant pressure value. Thus the pressure disturbance should be taken account into the control strategy to avoid frequent frequency oscillation. 


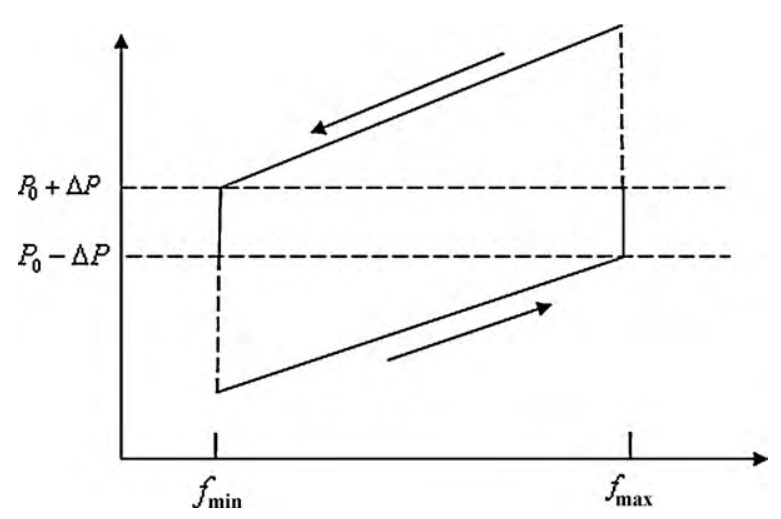

Fig. 5. Control schematic diagram of frequency adjustment.

\section{Model amendment}

\subsection{Frequency adjustment}

The above experimental results demonstrate that the impact of the discharge pressure disturbance on the frequency should be taken account into the control model of frequency adjustment. The pressure objective is revised as $P_{o b j} \in\left[P_{0}-\Delta P, P_{0}+\Delta P\right]$. Here, $P_{0}\left(P_{0}=28\right.$ bar $)$ and $\Delta P$ are, respectively, constant discharge pressure objective and pressure disturbance. The appropriate value of pressure disturbance $\Delta P$ is determined to be 1 bar based on the experimental analysis.

The operation frequency is adjusted by the host module in accordance with the objective pressure region and distributed to every module in terms of Eq. (1). The control schematic diagram is shown in Fig. 5.

\subsection{Module switching condition}

\subsubsection{Increase of thermo-on module}

Under the promise of Eqs. (2a) and (2b), the condition of increasing module number is revised as below.

The current discharge pressure of the host module should satisfy Eq. (8), which indicates there is a need to increase the number of thermo-on module.

$P_{d 1, \text { cur }}<P_{0}-2 \Delta P$

And the total operation frequency must increase to a certain frequency allocation point, which is expressed as Eq. (9)

$$
\sum_{i=1}^{i=N} f_{i, N} \geq f_{n \rightarrow n+1}
$$

Furthermore, considering the lag between pressure change and frequency adjustment, a certain judgment time $t_{j}$ is defined in the model. When Eqs. (8) and (9) can be obtained, the timer in the circuit board begins to record running time. If the running time is larger than $4 \mathrm{~min}$, i.e. $t_{j}>4 \mathrm{~min}$, the module switching begins to be carried out. Or else, the timer resets, and then restarts to record the running time when Eqs. (8) and (9) can be satisfied again.

\subsubsection{Decrease of thermo-on module}

Under the premise of Eqs. (5a) and (5b), the following conditions are necessary.

The current discharge pressure of the host module must satisfy Eq. (10), which indicates that there is a need to decrease the number of thermo-on module.

$$
P_{d 1, \text { cur }}>P_{0}+2 \Delta P
$$

And the total operation frequency must drop to a certain frequency allocation point, which is expressed as Eq. (11)

$$
\sum_{i=1}^{i=N} f_{i, N} \leq f_{n \rightarrow n-1}
$$

Similarly, a certain judgment time, $4 \mathrm{~min}$, is necessary to determine whether the condition of decrease of thermo-on module can be obtained, which is expressed as $t_{j}>4 \mathrm{~min}$.

\subsection{Model of frequency allocation}

Considering the fact that when the module switching is carried out and the module number increases, the operation frequency will sharply drop to result in lower discharge pressure, inferior heating effects and oscillation of the system if frequency is equally allotted to every thermo-on module during the module switching. In order to solve these problems, the frequency allocation can be performed according to Eq. (12) during the module switching.

$\sum_{i=1}^{i=N} f_{i, c u r}=\left\{\begin{array}{l}(n-1) a+x, \quad x<a \\ n b, \quad x \geq a\end{array}\right.$

Here $a, x$ are, respectively, constant frequency value distributed to pre-existing thermo-on module(s) and variable frequency value ensuing thermo-on module, which is adjusted by the host module. And $b$ is the operation frequency equally allocated to every module when $x \geq a$.

When the current discharge pressure can satisfy Eq. (13) for 4 min after the completion of frequency allocation, the operation frequency will be equally distributed to every module in accordance with Eq. (14).

$\left|P_{d}-P_{0}\right|<2$ bar

$f_{i, N}=\frac{\sum_{i=1}^{i=N} f_{i, \text { cur }}}{n}+\frac{\Delta f}{n}$

However, when the module switching is carried out and the module number decreases, the phenomenon of sharp frequency reduction does not happen. Thus the operation frequency is equally allocated to every thermo-on module so as to realize suction pressure balance among modules and oil balance among different compressors. The operation frequency allocation model can be expressed in Eq. (15).

$\sum_{i=1}^{i=N} f_{i, c u r}=n b$

The model of frequency allocation can be explained in Fig. 6.

\section{Experimental results and discussion}

\subsection{Increase of module number}

\subsection{1. $f_{n \rightarrow n+1}=110,210 \mathrm{~Hz}$ and $a=70$}

In the control program, $f_{n \rightarrow n+1}$ are determined to be $110 \mathrm{~Hz}$ and $210 \mathrm{~Hz}$, respectively, when one module is switched to two module, and two modules are switched to three modules, i.e. $\left.f_{n \rightarrow n+1}\right|_{n=1}=$ $110 \mathrm{~Hz}$ and $\left.f_{n \rightarrow n+1}\right|_{n=2}=210 \mathrm{~Hz}$. Furthermore, the parameter $a$ is determined to be $70 \mathrm{~Hz}$. The experiment was made under the same condition as that in Section 3.2. The experimental results are shown in Fig. 7.

Compared analysis of Figs. 7 and 4 show that when the revised model was adopted to control the system operation, the frequency 

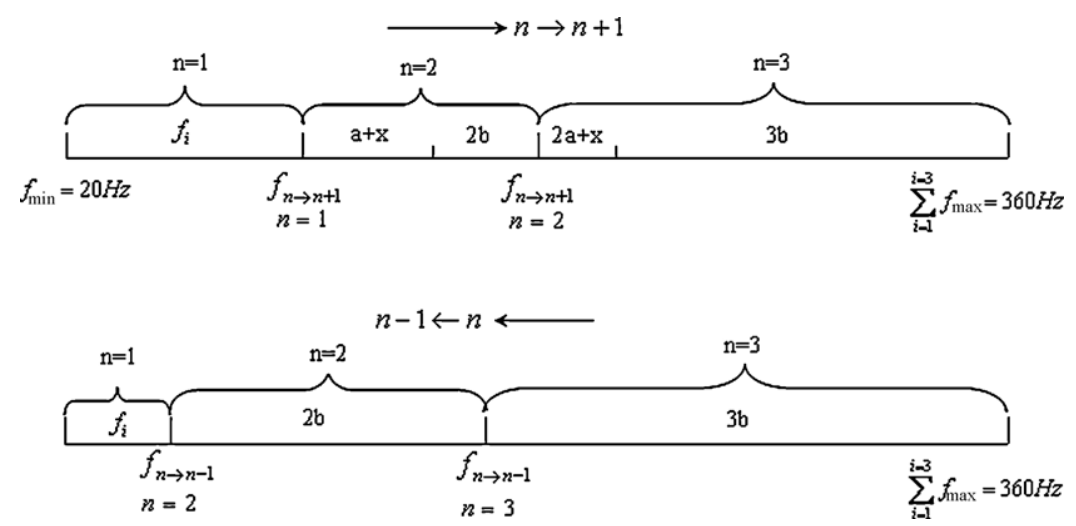

Fig. 6. Revised mode diagram of module switching and frequency allocation.

up to $100 \mathrm{~Hz}$ did not satisfy the module switching condition, and the host module ran stably for $3 \mathrm{~h}$.

\subsection{2. $f_{n \rightarrow n+1}=90,180 \mathrm{~Hz}$ and $a=70$}

Similarly, in the control program, $\left.f_{n \rightarrow n+1}\right|_{n=1}$ and $\left.f_{n \rightarrow n+1}\right|_{n=2}$ are, respectively, determined to be $90 \mathrm{~Hz}$ and $180 \mathrm{~Hz}$. The low temperature heating experiment was made under the same condition and the experimental results are shown in Fig. 8.

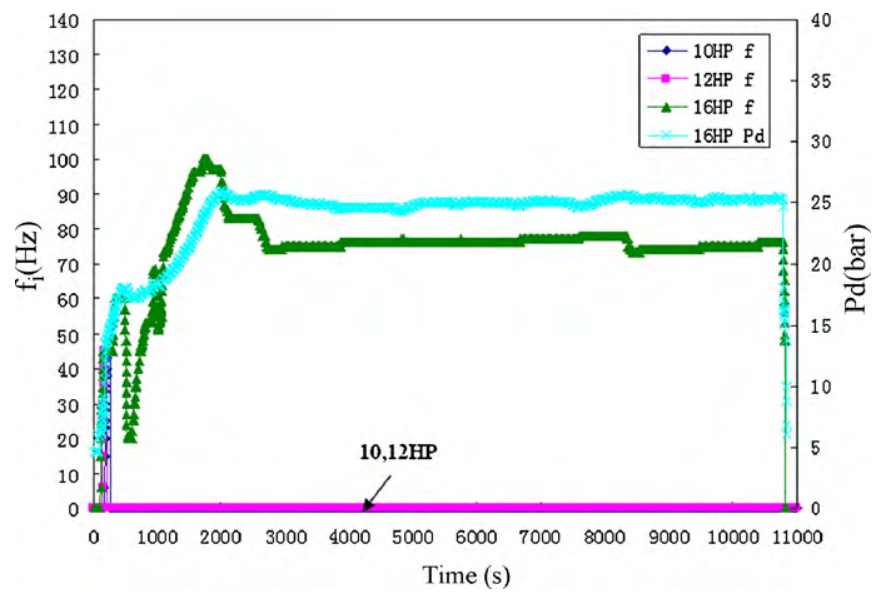

Fig. 7. Experimental results of low temperature heating controlled by revised model when $\left.f_{n \rightarrow n+1}\right|_{n=1}=110,\left.f_{n \rightarrow n+1}\right|_{n=2}=210,\left.f_{n \rightarrow n-1}\right|_{n=2}=40,\left.f_{n \rightarrow n-1}\right|_{n=3}=160$ and $a=70$.

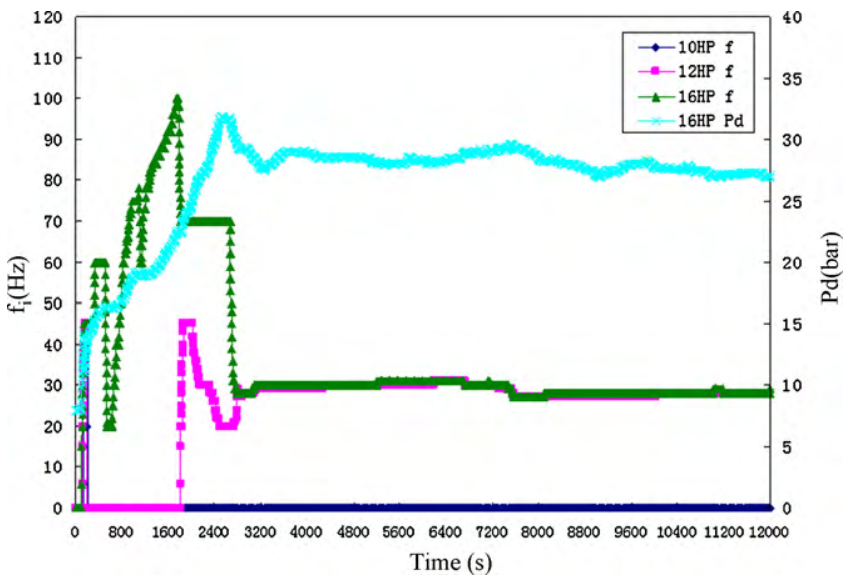

Fig. 8. Experimental results of low temperature heating controlled by revised model when $\left.f_{n \rightarrow n+1}\right|_{n=1}=90,\left.f_{n \rightarrow n+1}\right|_{n=2}=180,\left.f_{n \rightarrow n-1}\right|_{n=2}=40,\left.f_{n \rightarrow n-1}\right|_{n=3}=160$ and $a=70$.
Fig. 8 shows that the module switching condition could be satisfied and frequency allocation was carried out in accordance with the revised model, and the switching process was stable and almost no pressure fluctuation appeared. The host module and one slaver module ran in lower frequency, which is conducive to achieving suction pressure balance and oil balance, and reducing compressor noise.

Compared analysis of Figs. 7 and 8 show that the frequency allocation points are critical for module switching. If they are set too low, the module switching condition can be easily met. On the contrary, if they are set too high, the module switching cannot be performed. Thus one or two modules run at high frequency, which results in large power consumption. Obviously, the frequency allocation point $\left.f_{n \rightarrow n+1}\right|_{n=1}=90 \mathrm{~Hz}$ is more reasonable for VRF AC.

In order to verify the feasibility of the revised heating control strategy and reasonability of the frequency allocation point $\left.f_{n \rightarrow n+1}\right|_{n=2}=180 \mathrm{~Hz}$, the indoor units with $50 \%$ capacities were turned on to make low temperature heating experiment for a long time under the condition of $-10^{\circ} \mathrm{C} \mathrm{DB} /-15^{\circ} \mathrm{C} W B$ in the outdoor chamber and $20^{\circ} \mathrm{C} \mathrm{DB} / 15^{\circ} \mathrm{C} \mathrm{WB}$ in the indoor chamber. The experimental results are shown in Fig. 9.

Fig. 9 shows that the system ran stably for 7 defrosting cycles, frequency was stably adjusted in accordance with the revised pressure objective region, and the module switching could be performed in terms of the revised control model with frequency allocation point $\left.f_{n \rightarrow n+1}\right|_{n=2}=180 \mathrm{~Hz}$. In order to further verify feasibility of the control strategy used in VRF AC, two $140 \mathrm{~N}$ indoor units were turned off from the wired controller after the end of defrosting, and then turned on. The experimental results show that the slaver module, $10 \mathrm{HP}$ outdoor unit, stopped after the two $140 \mathrm{~N}$

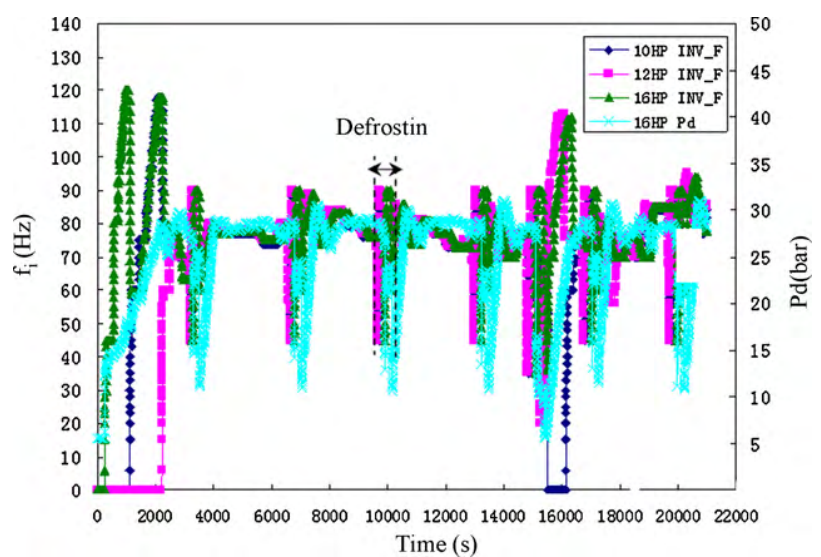

Fig. 9. Experimental results of module number increase under the condition of low temperature heating. 


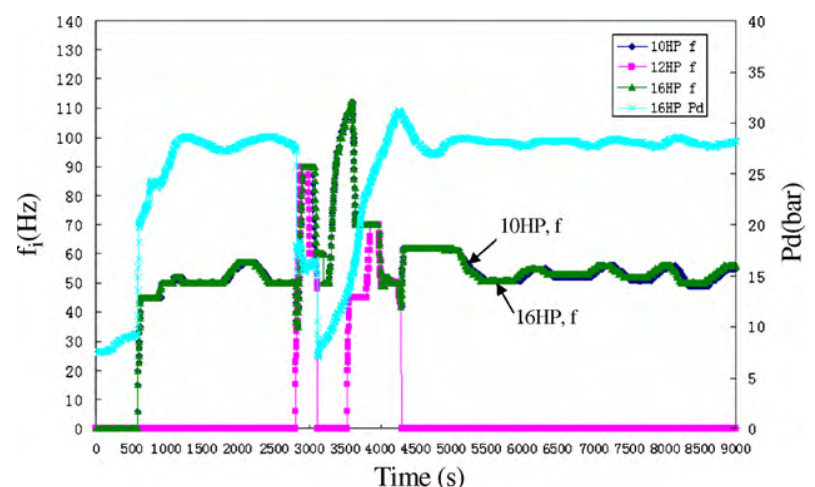

Fig. 10. Experimental results of module number decrease under the condition of normal heating.

indoor units were thermo-off, and then started to run stably after the two indoor units were thermo-on.

The experimental results demonstrate that the control strategy with the determined frequency allocation points $\left.f_{n \rightarrow n+1}\right|_{n=1}=90$ and $\left.f_{n \rightarrow n+1}\right|_{n=2}=180$ can realize reliable operation, stable module switching and frequency allocation for VRF AC.

\subsection{Decrease of module number}

Frequency allocation points $f_{n \rightarrow n-1}$ are determined to be $40 \mathrm{~Hz}$ and $160 \mathrm{~Hz}$, i.e. $\left.f_{n \rightarrow n-1}\right|_{n=2}=40$ and $\left.f_{n \rightarrow n-1}\right|_{n=3}=160$, respectively, when two modules are switched to one module and three modules are switched to two modules. The phenomenon of module number reduction appeared when the indoor units with $25 \%$ capacities were turned on to make nominal heating experiment under the condition of $7{ }^{\circ} \mathrm{C} \mathrm{DB} / 6^{\circ} \mathrm{C}$ WB in the outdoor chamber and $20^{\circ} \mathrm{C}$ $\mathrm{DB} / 15^{\circ} \mathrm{C} \mathrm{WB}$ in the indoor chamber. In detail, the discharge pressure dropped after the end of defrosting, the operation frequency began to increase to meet the pressure objective, and the module switching condition was obtained, so the second slaver module started to run. Subsequently, the discharge pressure increased to enhance heating effects, and then reached, or even surpassed the pressure objective, thus operation frequency began to drop, and the condition of decreasing module number was obtained. So the second slaver module stopped. Then, the system could run stably. The experiment shows that the whole running process is stable, the frequency allocation point $\left.f_{n \rightarrow n-1}\right|_{n=3}=160$ is reasonable and the control strategy is feasible for VRF AC with multi-module.

As for the frequency allocation point $\left.f_{n \rightarrow n-1}\right|_{n=2}=40$, when the operation frequency of every module reaches $20 \mathrm{~Hz}$ and the discharge pressure is higher than the pressure objective region, the slave must be thermo-off because the minimal operation frequency of the compressor is $20 \mathrm{~Hz}$. Moreover, the frequency difference $50 \mathrm{~Hz}$ between the frequency allocation point $90 \mathrm{~Hz}$ from one module to two modules and $40 \mathrm{~Hz}$ from two modules to one module is large enough to avoid occurrence of frequent module switching. And the phenomenon did not happen in heating experiment for a long time (Fig. 10).

And then a large number of long term experiments under different ambient temperatures have demonstrated the feasibility of the heating control strategy and reasonability of the frequency allocation points.

\section{Conclusions}

The heating control strategy is a key technology for VRF AC to ensure stable running and realize energy-saving. Inappropriate control will lead to frequent frequency fluctuation and module switching. The following control strategies can solve these problems and achieve proper running results.
The host module and slaver module(s) are defined in a set of VRF AC. The host module adjusts the frequency according to its discharge pressure, and allocates frequency to every thermo-on module in accordance with equal frequency allocation principle so as to balance suction pressure among modules and realize stable running. The synoptic heating control strategy can avoid control logic confusion, control complexity and unstable operation.

Heating control model has been built, which includes heating frequency adjustment, the module switching condition and frequency allocation model. For frequency adjustment measure, considering the fact that a small pressure disturbance will lead to frequency fluctuation, the constant pressure objective is revised to be a certain discharge pressure region. Thus the frequency can be stably adjusted and allocated to every module. In the module switching condition, taking into account the lag between pressure and frequency adjustment, the restriction condition of the current discharge pressure and the judgment time are introduced into the model to avoid frequent module switching. Furthermore, different frequency allocation models have been built for increase and decrease of module number. In the model, when the module number increases and evenly allotted frequency to every module is less $70 \mathrm{~Hz}$, one or two certain frequencies $70 \mathrm{~Hz}$ are distributed to the pre-existing thermo-on module(s) and the remaining frequency is distributed to ensuing thermo-on module so as to avoid sharp frequency fluctuation and inferior heating effect. A large number of experiments demonstrate the feasibility of the control strategy.

The frequency allocation points $f_{n \rightarrow n+1}$ are critical for module switching. If they are set too low, the module switching condition can be easily met. On the contrary, if they are set too high, module switching cannot be performed. The values are reasonably determined to be $90 \mathrm{~Hz}$ and $180 \mathrm{~Hz}$, respectively, when one module is switched to two modules and two modules are switched to three modules. And they are determined to be $40 \mathrm{~Hz}$ and $160 \mathrm{~Hz}$, respectively, when module number decreases, respectively, from two modules to one module and from three modules to two modules.

\section{Acknowledgement}

The authors would like to thank the experimental support from Haier Air-Conditioning Electronic Co. LTD.

\section{References}

[1] J.M. Choi, Y.C. Kim, Capacity modulation of an inverter-driven multi-air conditioner using electronic expansion valves, Energy 28 (2003) 141-155.

[2] T.N. Aynur, Variable refrigerant flow systems: a review, Energy and Buildings (2010) 1106-1112.

[3] C. Wu, Z. Xingxi, D. Shiming, Development of control method and dynamic model for multi-evaporator air conditioners (MEAC), Energy and Conversion 46 (3) (2005) 451-465.

[4] J.-L. Lin, T.-J. Yeh, Control of multi-evaporator air-conditioning systems for flow distribution, Energy Conversion and Management 50 (2009) 1529-1541.

[5] M. Masuda, K. Wakahara, K. Matsui, Development of a multi-split system air conditioner for residential use, ASHRAE Transaction 97 (2) (1991) 127131.

[6] W. Shi, Investigation on Characteristic and Control Strategy of Variable Refrigerant Flow Air Conditioning System [D], Tsinghua University, China, 2000.

[7] S. Shao, W. Shi, X. Li, et al., Performance and control scheme of compressor and condenser in VRF air conditioning system, Compressor Technology 171 (1) (2002) 1-4.

[8] W. Shi, S. Shao, X. Peng, Q. Yan, Simulation study on control strategy of MVRV air conditioning system with heat recovery, HV\&AC 33 (1) (2003) 12-17.

[9] J. Xia, E. Winandy, B. Georges, J. Lebrun, Testing methodology for VRF systems, in: 9th International Refrigeration and Air Conditioning Conference at Purdue in USA, 2002.

[10] C. Wu, Z. Xingxi, D. Shiming, Development of control method and dynamic model for multi-evaporator air conditioners (MEAC), Energy Conversion and Management 46 (2005) 451-465.

[11] T.N. Aynur, Y. Hwang, R. Radermacher, Field performance measurements of a VRV AC/HP system, in: 11th International Refrigeration and Air Conditioning Conference at Purdue in USA, 2006.

[12] Design, Installation \& Testing Instruction of VRVIII R-410A Heat Pump, Daikin 2006. 